\title{
Problemas de las empresas cooperativas en México que atentan contra su naturaleza especial
}

\author{
Dra. Martha E. Izquierdo Muciño*
}

Recibido: $\quad 18.05 .09$

Aceptado: 24.06 .09

\begin{abstract}
Sumario: Introducción,-1. Origen del cooperativismo en México,-2. Ley general de sociedades cooperativas de 1927,-3. Ley general de sociedades cooperativas de 1933,-4. Ley general de sociedades cooperativas de 1938,-5. Ley general de sociedades cooperativas de 1994,-6. Problemas de las empresas cooperativas en México que atentan contra su naturaleza especial y propuestas.
\end{abstract}

Resumen: La figura del cooperativismo contiene en si misma valores y principios éticos que la hacen distinta de las demás empresas toda vez que las finalidades que persigue son totalmente diferentes. Estos principios en el año de 1995 fueron reiterados por la Alianza Cooperativa internacional en un congreso celebrado por motivo de sus cincuenta años de existencia. Por tanto es necesario saber si aún conservan los valores y principios que caracterizan a las empresas cooperativas en nuestro país, toda vez que a juicio de muchos analistas, la actual Ley General de Sociedades Cooperativas (1994), trastoca esos valores y por tanto tiende a desnaturalizarlas ya que ante el reto por competir con el mercado globalizado se van asimilando paulatinamente a la Sociedad Anónima, cuya finalidad difiere radicalmente de la empresa cooperativa.

Palabras clave: cooperativismo, principios y valores del cooperativismo, desnaturalizacion de las empresas cooperativas.

Abstract: The Cooperatism figure contains on itself ethic values and principles that make it different among other enterprises based on its own purposes that complete differs from the others. Those principles were reiterated in year 1995 by the International Cooperative Alliance in a congress organized to celebrate its 50 years of life. For the above statement, this is necessary

* Doctora en Derecho por la Universidad Nacional Autónoma de México (UNAM), Catedrática e Investigadora de la Universidad Autónoma del Estado de México (UAEM), adscrita al Sistema Nacional de Investigadores (SNI), e investigadora de la Asociación Internacional de Derecho Cooperativo (AIDC) con publicaciones diversas sobre temas de Derechos Humanos, Derecho Social y Derecho Internacional Para la Paz. 
to know if these enterprises keep the same values and principles that characterized a cooperative enterprise in our country. The latest obeys to the opinion of some analyzers where according to their judgments, the current General Law for Cooperative Societies (1994) confuses and alter the values of the enterprises so the tendency is to change their nature; in front of a challenge to compete against the globalize market these enterprises are gradually being transformed into an Anonymous Society which its purpose radically differs to the Cooperative Enterprises.

Key words: cooperatism, cooperatism values and principles, change in nature of the cooperative enterprises. 


\section{Introducción}

La crisis generalizada de los países latinoamericanos, ha vuelto a poner en boga nuevamente la alternativa cooperativista y autogestionaria, en medio de la desesperación social, del hundimiento de la productividad, las altas tasas de desempleo y la marginalidad de nuestras sociedades, lo cual nos obliga a reflexionar acerca de una alternativa más viable, más justa y más humana.

Esta crisis generalizada nos hace voltear los ojos hacia la creación de empresas cooperativas y autogestionarias como alternativas de solución, ante el resquebrajamiento paulatino de las estructuras social y económica, provocado por la desigualdad social en México.

A pesar de la diversidad de alternativas existentes, la economía social y solidaria es hoy una realidad, ha encontrado y encuentra obstáculos para su efectiva instrumentación y desarrollo pero contiene dinamismos propios y concretizadores en todo el mundo que la hacen confiable como camino y propuesta de cambio de relación del hombre con su entorno productivo y del hombre con el hombre.

Sea que la economía social y solidaria se materialice en empresas cooperativas genuinas de gran envergadura o en formas incipientes de participación social o familiar, es sin duda un modelo que desafía concretamente a las formas individualistas y capitalistas de producción y distribución de bienes servicios y crédito. El carácter solidario de éste modo, está dado por su humanismo intrínseco, comprometiendo la misma administración de las empresas.

Por lo anterior consideramos que al potenciar el desarrollo cooperativista mexicano y sistemas de autogestión, se podrá promover la participación de los sectores populares en la creación de un estilo de desarrollo de naturaleza alternativa al prevaleciente.

La figura del cooperativismo contiene en si misma valores y principios éticos que la hacen distinta de las demás empresas toda vez que las finalidades que persigue son totalmente diferentes. Estos principios en el año de 1995 fueron reiterados por la Alianza Cooperativa internacional en un congreso celebrado por motivo de sus cincuenta años de existencia.

El presente trabajo tiene como objetivo fundamental llevar a cabo un análisis jurídico de tipo documental de las distintas leyes que en materia cooperativa han existido en México, con la finalidad de saber si aún conservan los valores y principios que caracterizan a las empresas cooperativas, toda vez que a juicio de muchos analistas, la actual Ley General de Sociedades Cooperativas (1994), trastoca esos valores y por tanto tiende a desnaturalizarlas. 
Toda vez que ante el reto por competir con el mercado globalizado se van asimilando paulatinamente a la Sociedad Anónima, cuya finalidad difiere radicalmente al de la empresa cooperativa, puesto que el cooperativismo es un sistema que se diferencia de los demás por su muy peculiar naturaleza y por su forma muy especial de satisfacer las necesidades individuales y colectivas, constituyendo un sistema alternativo al actual modelo neoliberal que puede coadyuvar a eliminar la injusticia social y a reducir los niveles de pobreza, de tal suerte que sería un error cambiar el espíritu de lucro personal de las actividades económicas de ayuda mutua, por el de lucro personal de las actividades económicas.

\section{Origen del cooperativismo en México}

Los orígenes del cooperativismo en México se ubican en 1839, fecha en que se fundó en Orizaba Veracruz la primera Caja de Ahorros con las características de una sociedad cooperativa.

Sus fundadores fueron empleados y artesanos, inspirados en ideas de cooperación y ayuda mutua, que en un tiempo les fueron transmitidos por los socialistas utópicos franceses.

En efecto, el cooperativismo fue una idea novedosa venida de Europa, que albergo los sueños de los obreros de la industria en México, dado que sometidos a la esclavitud del capital, lograron formar rápidamente el Circulo Obreros de México, organizando posteriormente (septiembre de 1873) el Primer Taller Cooperativo del cual surgiría la Primera Sociedad Cooperativa de México, integrada por un reducido número de 26 sastres de la Ciudad de México.

El ejemplo de esta primera sociedad cooperativa motivó la transformación de algunas sociedades mutualistas en cooperativas, como fue «La Sociedad Progresista de Carpinteros» que formada por 32 miembros, en 1874 decidieron liquidar su sociedad mutual para convertirla en una sociedad cooperativa y de consumo denominada: "Compañía Cooperativa de Obreros de México».1

De igual manera otras sociedades mutualistas se transformaron en cooperativas de producción como: "La Fraternal de Sombreros» y la «Sombrerera Mexicana La Huelga». Posteriormente en 1876 se fundó la primera Asociación Cooperativa de Consumo de Obreros Colonos, formada por los obreros ferroviarios de la estación de Buenavista.

1 Martínez Ramírez, Jorge Alberto y Rojas Herrera, Juan José. «Panorama del sector cooperativo mexicano». Revista UNIRCORP Américas, Volumen 1 número 2, noviembre 2003, Universidad de Sherbrooke. P 201 
Estas ideas de cooperación y ayuda mutua tuvieron en nuestro país un efecto muy particular pues al ser defendidas por los socialistas utópicos franceses, así como por ideólogos anarquistas, vinieron a constituir lo que en nuestra tradición existía en las comunidades indígenas como el trabajo colectivo y la propiedad comunal de las tierras en los famosos: «calpullis».2

En consecuencia puede afirmarse que las instituciones de tipo cooperativo que surgieron en México, nacieron en medio de grandes luchas sociales y agitaciones populares en defensa de tales ideas, identificándose desde sus inicios con los movimientos: campesino y obrero (1800 a 1903).

Asimismo en nuestro país han existido diversas leyes cooperativas que reflejan su momento histórico, como a continuación veremos:

El precursor legal de las empresas cooperativas lo fue el Código de Comercio de 1889-1890, en virtud de que en su capítulo VII les dedicó 22 preceptos y las consideró como sociedades mercantiles confundiéndolas con la sociedad anónima, que bien podía construirse con responsabilidad limitada o ilimitada y nunca se les concedió ningún tratamiento especial.

En el Código de Comercio las sociedades cooperativas fueron consideradas como una variante de las sociedades mercantiles y fueron definidas como empresas con todas sus características generales como fueron: número de socios, capital variable, responsabilidad solidaria e ilimitada o limitada a una determinada suma menor igual o mayor que el capital social, etc.

Posteriormente una de las grandes aportaciones que trajo consigo la revolución de 1910 fue que al establecerse la Constitución de 1917 trajo consigo un nuevo orden social y económico así como un nuevo proyecto nacional, consecuentemente al crearse las bases para un sector social de la economía se insertaron automáticamente las empresas cooperativas, delimitadas por los artículos: 25, 27, 28, 31 F. IV; 73 F. VII y X; 123 y 131 Constitucionales.

En efecto, la constitución de 1917 se refirió a las cooperativas en los artículos 28 párrafo 40; (actualmente articulo 7 y 123 apdo. A Frac. XXX), en forma «tangencial y casualmente», según lo menciona Alfonso Labriega (2) dado que en las diversas excepciones que existen en dicho precepto menciona a dos que son: a) en favor de las asociaciones de trabajadores y b) en apoyo a las asociaciones o sociedades cooperativas de productores,

2 Los Calpulli constituían la pequeña propiedad de los indígenas cuyos caracteres cooperativos del régimen de propiedad estaban representados por tierras del barrio de tipo familiar unidas para facilitar la irrigación. 
ambas excepciones vienen a ser consecuencia de la libertad de asociación que consagra el artículo 9 Constitucional, así como la libertad de sindicalización de que nos habla el artículo 123 Apdo. A. F.XVI. ${ }^{3}$

Cabe mencionar que en el proyecto original (de Venustiano Carranza) no existían estas dos fracciones si no que estas surgieron posteriormente con la intención de fortalecer al mercado del henequén en Yucatán (Estado de Mérida) y por iniciativa de la diputación Yucateca.

Mucho se ha discutido ya si en el congreso constituyente se utilizó simplemente la palabra; "sociedad cooperativa de productores» como sinónimo de asociación de productores sin la intención de ver en ello más que una asociación.

En contraposición a esta opinión Alfonso Labriega menciona que al entre sacar uno de los pasajes del Diario de los Debates de los Constituyentes se observa que sí se tenía una clara visión del mensaje que como alternativa económica, traían estas empresas al mencionar:

«Si lo que los agricultores yucatecos han hecho en esta forma cooperativa establecida últimamente, lo hiciesen los productores de otros Estados con sus principales productores cuando se trata de exportar estos del extranjero, seguro que se obtendría en toda la nación una utilidad no menor de 80 a 100 millones de pesos al año, este dinero entrando en circulación nos traería desde luego una prosperidad efectiva». (Dictamen, 39 Serie Ordinaria, 12. 01. 1917). ${ }^{4}$

En consecuencia sostiene dicho autor que es indudable que el Art. 28 Constitucional encierra consigo lineamientos fundamentales para la política del país, que conforman el «Nuevo Derecho Constitucional Económico», abandonando con ello un liberalismo decimonónico y subordinando al interés de la sociedad los privilegios del individuo, confirmando que nuestra economía es una economía mixta en la que concurren los sectores público, social y privado. ${ }^{5}$

\section{Ley general de sociedades cooperativas (1927)}

La primera Ley General de Sociedades Cooperativas apareció en el Diario Oficial de la Federación el 23 de febrero de 1927, estando bajo el encargo presidencial el General Calles, que a diferencia del Código

\footnotetext{
3 Labriega Villanueva, Pedro A. La Reforma de legislación Mercantil (Recopilación). México. editorial Porrua.1985,p-203.

${ }^{4}$ Diario de Debates del Constituyente de 1917.

${ }^{5}$ Labriega, Pedro. Ob.cit. p. 204.
} 
de Comercio de 1889, propicia un ambiente legal y adecuado para las sociedades cooperativas.

Luís Hinostroza menciona: «la primera ley general de cooperativas fue promulgada el 10 de febrero de 1927 reconoce a las sociedades cooperativas agrícolas, industriales y de consumo. Esta ley fue muy progresista al autorizar objetivos múltiples para las cooperativas, sin embargo su vigencia fue breve, dadas las contradicciones existentes entre las disposiciones del texto legal y los fines mismos del cooperativismo. ${ }^{6}$

Se pensaba que era inconstitucional porque el Congreso no tenía facultades para legislar según la constitución de 1917 en materia de cooperativas, además la nueva ley no había derogado las disposiciones que sobre sociedades Cooperativas contenía el Código de Comercio de 1889».7?

Se acoge al sistema Raiffesen para las cooperativas agrícolas y al sistema Shultze-Delitzch para las industrias, particularmente en el concepto de la responsabilidad de los socios, que a semejanza de los métodos germanos sus características generales fueron:

a) Un voto a cada socio independientemente del número de acciones suscritas.

b) Las utilidades se repartirían de la siguiente forma: 20\% para el Fondo de Reserva, 10\% para los Consejos de Administración, Vigilancia y Gerencia, 70\% para los accionistas en proporción al capital pagado o al monto de las operaciones realizadas.

c) Los periodos se distribuían entre todos los accionistas y conforme al importe del capital suscrito o por partes iguales. La vigilancia oficial le fue encargada a la Comisión Nacional Bancaria.

d) Para tener personalidad jurídica se requería el reconocimiento de la Secretaría de Agricultura y Fomento ó de Industria Comercio y Trabajo y la inscripción en el Registro Público de Sociedades Cooperativas, dependiente del Registro Público de comercio.

De los Diarios de Debates de aquella época se entresacan los siguientes comentarios:

«Es una institución que defiende, precisamente los intereses tanto de los agricultores en pequeña como en grande escala, es una institución verdaderamente benéfica, aceptada con aplauso en el mundo entero. (Intervención de C. Espinosa. 46. ${ }^{a}$ sesión ordinaria. 17. 01. 1917)».8

${ }^{6}$ Hinostroza Fernández, Luis, Movimiento Cooperativo Internacional. México. Universidad Autónoma Metropolitana. 1989, p. 103.

7 Idem.

8 Diario de Debates del Constituyente de 1917. 
«La comisión reguladora del mercado del henequén no es más que una sociedad cooperativa de productores... (intervención del C. Alfonso Romero, $46 .{ }^{a}$ Sesión ordinaria, 17. 01. 1917)». ${ }^{9}$

La suprema corte sostuvo que las cooperativas que no se establecieran y funcionaran sujetándose a la ley de 1927 solo se consideraran como sociedades de Derecho común (S. J. F. T. XLI — Pág. 3572 longoria Agapito), así mismo establece: debe sobreseerse el amparo pedido por los representantes legítimos de una cooperativa de Industria, Comercio y trabajo. (s. j. f - t. XXXIV - P. 163 Gremio unido de alijadores de Veracruz).

Lo cierto es que esta ley no resulto como se esperaba, además de que no fueron derogados del Código de Comercio los artículos que mencionaban a esta figura y que la confundía con la sociedad anónima, además de no haber sabido establecer una clara distinción entre las sociedades mercantiles y las organizaciones sin fines de lucro, constituyéndose en una especie de hibrido extremadamente complejo que contribuyo muy poco a distinguir a la sociedad anónima de otras formas de organización social para la producción. ${ }^{10}$

\section{Ley general de sociedades cooperativas de 1933}

Con fecha 30 de Mayo de 1933 apareció en el Diario Oficial un nuevo ordenamiento que intentó enmendar las deficiencias de la ley anterior, tratando de ajustarse a los postulados tradicionales de la ideología cooperativa, adoptando con ellos criterios de legislaciones extrajeras que enarbolaban los principios de la doctrina cooperativa.

En el Diario Oficial de la Federación de :21,V.1934, se derogaron las disposiciones del código de Comercio relativos alas sociedades cooperativas (que se encontraban vigentes con la ley anterior) y se les dotó de un reglamento que no se tenía con la antigua ley .

De esta manera le fueron intercalados los postulados fundamentales de la ideología cooperativa, según fue considerado por el Congreso Cooperativo internacional celebrado en Viena, (agosto de 1930) como fue:

a) Cooperación abierta y adhesión voluntaria

b) Igualdad de los socios

c) Reingreso sobre las compras con interés limitado al capital

d) Neutralidad Política y religiosa

e) Venta al contado

9 Ídem.

10 Martínez Ramírez, ob.cit. p. 203. 
f) Constitución de un fondo de propaganda y educación

g) Así mismo le fue permitida a toda persona, la posibilidad de crear empresas cooperativas y no solamente a trabajadores (como anteriormente se elegía), con el número de Diez personas, los menores de edad (con 16 años cumplidos) también tenían la posibilidad de ingresar a las sociedades cooperativas de responsabilidad limitada, y se aceptó el ingreso de extranjeros. Estableciéndose como regla general que los cooperativos fueran de responsabilidad limitada.

h) Se habló de certificados de aportación ( y no de acciones) y se exigió la constitución de fondos de reserva y de previsión social y especial, con la características de que el primero era irrepartible.

i) Se siguió conservando el principio de un voto por cada socio y las cooperativas fueron clasificadas de cuatro formas: a) de consumidores, b) de productores, c)Mixtos, d) de intervención oficial.

j) Esta ley dedicó mayor atención a las cooperativas de consumo y se admitió a los asalariados en ellas.

k) La constitución de las cooperativas se facilito mediante una simple acta que satisficiera los requisitos legales, que estuviera autorizada por la Secretaría de Economía Nacional, habiéndose inscrito en el Registro Publico de Comercio.

I) Se aludió por $1 .^{\text {a }}$ vez aunque en forma breve a las cooperativas escolares de cuya regulación se encargó la Secretaría de Educación Pública, sancionándose el uso indebido de la simulación y la negativa de recibir la inspección. ${ }^{11}$

m) Se respetó a las cooperativas constituidas conforme a la ley de Crédito Agrícola y se reglamentó la intervención de la Secretaría de Economía Nacional, de Agricultura y Fomento estableciéndose las federaciones y confederaciones de cooperativas.

Como se observa esta ley fue elaborada por una comisión de expertos que tomaron en cuenta los principios del cooperativismo Internacional y trataron de ajustarlos a la realidad Mexicana de los años 30.

Su vigencia fue de 5 años, habiendo sido derogada en 1938.

\section{Ley general de sociedades cooperativas de 1938}

La ley de1938, había sido considerada a juicio de muchas personas como una «magnífica ley», y sin embargo en el año de 1938 (Diario

11 Labriega Villanueva, ob.cit. p. 236. 
Oficial de la Federación. 15-II-1938), se promulgó una nueva Ley General de Sociedades Cooperativas; quedando derogada la ley anterior, así como su respectivo reglamento, al respecto comenta Pedro Labriega: «... es conveniente recordar primero la tendencia socializadora del régimen cardenista que seguramente se hizo plasmar en esta nueva ordenanza, segundo la intención de adecuar el nuevo ordenamiento cooperativo, con el estatuto cooperativo de la ley de sociedades mercantiles (aún vigente), que considera a la cooperativa como sociedad mercantil...».12

De las principales características de la ley de 1938 y de su reglamentación fue el hecho de que a diferencia de la ley anterior se establece que únicamente los trabajadores pueden formar parte de las sociedades cooperativas y se reiteran los principios de filosofía cooperativa con algunas modificaciones como son:

a) Principio de igualdad en obligaciones y derechos de los cooperadores.

b) Un voto por cada socio.

c) No perseguir fines de lucro.

d) Mejoramiento social y económico de c/u de sus miembros.

e) Capital variable.

f) No ingreso a los menores de edad.

g) Régimen de responsabilidad limitada y suplementada.

h) Prohibición expresa para los extranjeros para de ocupar puestos de dirección o administración.

i) Limitación para su ingreso en las cooperativas de productores.

j) Autorización para que estas sociedades se afiliaran.

k) Sujeción a las cooperativas escolares a un reglamento especial.

I) Constitución de las sociedades cooperativas mediante Asamblea General .

m) Creación del Registro Cooperativo Nacional a cargo de la secretaría de Economía Nacional.

n) Se suprimieron las cooperativas mixtas.

o) Se reglamentaron las cooperativas de intervención oficial y de partición estatal, así como de productores y consumidores.

p) Se fijaron montos para el monto de reserva y para el de previsión social.

q) Se facultó a los sindicatos de trabajadores para construir cooperativas de consumo.

r) Se indicaron los libros sociales que las cooperativas debían manejar. 
s) Se introdujo en las cooperativas de productores una comisión de control técnico para organizar y dirigir la producción

t) Su autorizó a las cooperativas (excepcionalmente) para utilizar servicios asalariados.

u) Se otorgó una amplia intervención de la Secretaría de Economía Nacional.

Esta facultad le fue heredada a la Secretaría del Trabajo que con el tiempo vino a compartir con las Secretarías de Relaciones Exteriores, de Hacienda, Trabajo, Educación Pública, Industria y Fomento Industrial, Pesca, Comunicaciones y Transportes, Energía Minas e Industria Paraestatal, Desarrollo Urbano y Ecología, denotándose en esta ley un noble deseo por el desarrollo de las cooperativas de producción. ${ }^{13}$

De hecho puede decirse que el sexenio del Presidente Lázaro Cárdenas (1934-1940) fue el periodo de ascenso para el movimiento cooperativo mexicano, ya que el gobierno cardenista propició la constitución de cooperativas tanto en el campo como en la Ciudad. Este programa respondía a una política de gran apoyo al cooperativismo que tuvo su máxima expresión en el plan sexenal, cuyas ideas iban tendientes a fortalecer el aparato estatal para convertirlo en un promotor del desarrollo económico y social.

El cooperativismo en ese entonces se concibió como un sistema apropiado para organizar empresas productivas y promover socialmente a contingentes de trabajadores bajo la idea de ampliar y fortalecer al movimiento cooperativo aún bajo el capital extranjero, lo cual motivó al cardenismo para renovar al cooperativismo mexicano sobre bases más firmes, más populares y solidarias con los sectores obreros y campesinos.

Durante el sexenio cardenista se autorizó el registro de cerca de mil cooperativas en las que se incorporaron 131.739 socios, cifras que en aquel momento representaron un verdadero récord. ${ }^{14}$

Luís Hinostroza comenta: "Estos planteamientos significaban una clara posición de clase con respecto al cooperativismo, definiéndolo como un instrumento para la cooperación y el trabajo asociado, válido tanto para el campo como para la ciudad». ${ }^{15}$

Por lo anterior podemos afirmar que desde los años 30 el movimiento cooperativo mexicano ha estado ligado directamente a los avances retrocesos que ha sufrido el movimiento popular, sin embargo una de las criticas que se hacen a ésta ley es que no obstante su marcado corte

\footnotetext{
13 Labriega, Pedro, ob. cit. p. 238.

14 Martínez Ramírez. ob.cit. p. 206.

15 HinOSTROZA, Luís. ob.cit. p. 105.
} 
clasista, impuso una estructura centralista y unitaria de representación gremial, de carácter cupular y legitimó el intervencionismo estatal en la vida interna de las cooperativas, quedando el movimiento cooperativo subordinado a los intereses del Estado. ${ }^{16}$

\section{Ley general de sociedades cooperativas de 1994}

En el mes de junio de 1994. (Diario Oficial de la Federación, Junio 1994) se emitió una nueva Ley General de Sociedades Cooperativas, en la exposición de motivos se mencionó la necesidad de actualizar la ley de 1938 atendiendo al sector social de economía, habiéndose realizado 14 foros a nivel nacional, así como diversos estudios de la legislación cooperativa en otros países, que habían destacado en su economía en base al sistema cooperativo, como era el caso de España, Francia, Italia, Alemania, Colombia, Israel, Inglaterra, Costa Rica, Panamá, Chile, entre otros. ${ }^{17}$

Entre las demandas de cambio se detectaron como de las más importantes:

a) Eliminación y control de vigilancia por parte del ejecutivo.

b) Acceso a los organismos jurisdiccionales a nivel local y regional, que puedan resolver de manera más ágil las controversias que se susciten.

c) La desconcentración del registro ejercida en cada estado incluso a nivel municipal.

d) Simplificación administrativa.

e) Necesidad imperiosa de capacitación tanto cooperativa como de aquellos aspectos que de alguna manera coincida con la materia.

f) Necesidad de facilitar un acuerdo de desarrollo económico y comercial con acceso al financiamiento.

h) Preservación de los principios y derechos de previsión social, y sobre todo una sólida organización que permita la integración cooperativa a nivel nacional.

En este orden de ideas la Comisión de Fomento Cooperativo enfatizó sus objetivos de: actualización, regulación, simplificación de administración interna y se otorgaron opciones de crecimiento.

\footnotetext{
16 Martínez Ramírez. ob.cit. p.205.

17 Véase exposición de motivos de la Ley General de Sociedades cooperativas de 1994.
} 
En el título primero se habla por primera vez de «acto cooperativo», para diferenciarlo de otros actos jurídicos.

Se define también por 1 . $^{\mathrm{a}}$ vez lo que debe entenderse por sistema cooperativo y movimiento cooperativo y se establece la observancia obligatoria de los principios del cooperativismo mundial, como parte de la economía solidaria.

En el título II se dispone que las sociedades cooperativas y sus organismos superiores, pueden constituirse y operar en todos los campos de la economía nacional, adquiriendo su propia personalidad jurídica al momento mismo de su constitución, borrando con esto desventaja frente a otras sociedades.

El registro de los organismos del sector social deberá hacerse ante el Registro Público de Comercio, toda vez que no existe una institución similar en exclusiva para estos organismos..$^{18}$

En el título IV se establece un apoyo del gobierno federal y los Estados, que deban proporcionar a todas las instituciones de vocación cooperativa, así como a los organismos cooperativos.

En base, a lo anterior la Comisión de Fomento Cooperativo consideró que esta ley respondía a las necesidades requeridas para el sector cooperativo, adecuándola en algunas de sus partes, como en lo relativo a la organización y administración interna cuyo diseño se dejo como facultad a la Asamblea Constitutiva y para las acciones de fomento y se reconoció el papel que debían adquirir las instituciones de asistencia técnica.

Se contempló la necesidad de crear un tribunal de lo contencioso cooperativo para dar más agilidad a la solución de controversias, no obstante ello se utilizaron los órganos del poder judicial con representantes en los Estados y Municipios.

Otro aspecto trascendente de esta ley lo fue el hecho de considerar el ámbito económico de estas empresas, esto es: que en lugar de mencionar que las cooperativas no debían ser lucrativas o especulativas, se estimó conveniente que se manejaran sin limitar su participación "de manera discriminatoria» respecto a otras sociedades, pudiendo además participar en todos los campos de la economía, sin limitación alguna y con acceso a financiamientos con respaldos de garantía, con lo cual se deja entrever el giro que da este tipo de empresas cooperativas, se les abrió el campo dentro de las sociedades cooperativas de ahorro y préstamo para manejo los pequeños capitales de sus socios, en obras y acciones conjuntos para propiciar el ahorro. ${ }^{19}$

\footnotetext{
18 Idem.

19 Idem
} 
En efecto una de las virtudes de ésta ley fue que por primera vez se reconoce a las Cajas Populares de ahorro y préstamo como Sociedades Cooperativas, señalando la obligatoriedad por parte de la Administración Pública en sus tres niveles de apoyar a través de políticas públicas de fomento a ésta organización social, asumiendo también el compromiso de establecer las bases para la creación y reconocimiento de instituciones de asistencia técnica al sector cooperativo. ${ }^{20}$

Finalmente podemos decir que con esta nueva ley no se requería la expedición posterior de un «reglamento» como sucede actualmente con las sociedades civiles y mercantiles, permitiendo que la no previsión por la propia ley lo determine cada sociedad, según sea lo más conveniente para su estructura productiva.

Sin embargo el comentario que se ha hecho a esta ley es que lejos de contener un autentico espíritu cooperativista resultó ser una ley reguladora mas que de fomento y promoción al cooperativismo y si bien mostró algunos avances significativos como fue las plena autonomía tanto en su constitución como en su funcionamiento, han existido escasos avances a partir de su promulgación por parte del movimiento cooperativista nacional pues continúa estancado el crecimiento de estas empresas pese a las facilidades para su creación y registro. ${ }^{21}$

Asimismo se critica que dicha ley si bien liberó al movimiento cooperativo de la tula de Estado, la realidad es que lo puso a competir sin ningún tipo de salvaguardas en el mercado abierto, pues no vino aparejada con una real libertad asociativa ni fue producto de un verdadero reconocimiento del cooperativismo como palanca del desarrollo nacional ni como factor de integración social, de hecho puede decirse que ha vivido sin saber que rumbo tomar ni como sostenerse en el mercado sin la ayuda del aparato estatal, el cual cada vez mas imbuido de una ideología neoliberal ha demostrado una autentica falta de sensibilidad con este sector, abandonándolo a su suerte. ${ }^{22}$

\section{Problemas de las empresas cooperativas en México que atentan contra su naturaleza especial}

Alicia Kaplan de Drimer, reconocida investigadora en materia de cooperativas, realiza un interesante ensayo en el que destaca los princi-

20 Martinez Ramírez, ob.cit. p.207.

21 RuIz de Chávez, Mario. Apuntes inéditos tomados de la Cátedra sobre Cooperativismo. UNAM 1999.

22 Martínez Ramírez. ob.cit. p. 207. 
pales problemas por los que atraviesan actualmente las cooperativas en el mundo y que tienden a desnaturalizarlas. Dichos problemas los hace consistir fundamentalmente en:

1. Reducción del número de miembros.

2. Disposiciones respecto al capital.

3. Disposiciones respecto al reparto de reservas.

4. Participación de personas tradicionalmente extrañas.

5. Relajamiento en la disciplina de algunas normas.

6. Creciente diversidad y complicación de las disposiciones aplicables. $^{23}$

Sostiene dicha autora que cada uno de éstos problemas se hacen consistir en la desviación de los principios cooperativos con que operan este tipo de empresas en todo el mundo, como son:

1. Adhesión voluntaria.

2. Gestión democrática por parte de los socio.

3. Participación económica de los socios.

4. Autonomía e independencia.

5. Educación formación e información.

6. Cooperación entre cooperativas.

7. Interés por la comunidad.

Que ante el reto por competir con el mercado globalizado se van asimilando paulatinamente a la Sociedad Anónima, cuya finalidad difiere radicalmente al de la empresa cooperativa, pues como se ha mencionado ya el cooperativismo es un sistema que se diferencia de los demás por su muy peculiar naturaleza y por su forma muy especial de satisfacer las necesidades individuales y colectivas, constituyendo un sistema alternativo al actual modelo neoliberal que puede coadyuvar a eliminar la injusticia social y a reducir los niveles de pobreza, de tal suerte que sería un error cambiar el espíritu de lucro personal de las actividades económicas de ayuda mutua, por el de lucro personal de las actividades económicas.

Atento lo anterior y siguiendo parcialmente el modelo que realiza la citada autora respecto a la desnaturalización de las empresas en el mundo se procede a realizar un análisis jurídico de los principales problemas que enfrenta la empresa cooperativa en México y que pueden desvirtuar su naturaleza especial.

23 Kaplan de Drimer, Alicia. Mutaciones estructurales en las cooperativas. España. Ministerio del Trabajo y Asuntos Sociales y Dirección General de Fomento a la Economía Social. Editorial CIRIEC 1997 p. 104. 
- INDEFINICIÓN EN LA LEY: En primer lugar se observa que en las leyes cooperativas que han existido en México, existe una gran confusión respecto a su naturaleza jurídica pues si partimos de la idea de que las empresas cooperativas no son sociedades mercantiles, resulta un error agruparlas en ese rubro ya que deben reconocidas exclusivamente dentro del sector social de la economía como lo menciona el artículo 25 Constitucional desde 1983.

Luego es necesario que queden correctamente definidas estas empresas pues por un lado se les reconocen como sociedades mercantiles en el artículo $1{ }^{\circ}$ de la Ley General de Sociedades Mercantiles que menciona:

Art. 1.‥-Esta Ley reconoce las siguientes especies de sociedades mercantiles:

I. Sociedades en nombre colectivo;

II. Sociedades en comandita simple;

III. Sociedad de responsabilidad limitada;

IV. Sociedad anónima;

V. Sociedad en comandita por acciones y;

VI. Sociedad cooperativa...

Lo que las ubicaría dentro del sector privado pero al mismo tiempo el mencionado articulo 25 Constitucional las considera como integrantes del sector social de la economía, identificándolas como una forma de organización de carácter social para la producción, distribución y consumo de bienes y servicios socialmente necesarios... ${ }^{24}$

Se ha dicho que si bien el legislador se vio obligado a incorpóralas en la Legislación Mercantil fue por que no existía en aquel entonces disposición alguna que facultara al Congreso Federal para legislar sobre cooperativismo, por tal razón y con la finalidad de crear una ley que las regulara se incluyeron originalmente en el Código de Comercio a pesar de que es reconocido universalmente que dichas empresas no tienen el animo de lucro.

En efecto, la Carta Magna no otorga facultades al Congreso de la Unión para legislar en forma expresa en materia de cooperativas, a pesar de los artículos, 25, 28 párrafo 70, 27, 73, f. X, 123, F. 1. ${ }^{a}$ y apartado. A F XXX Constitucionales como se analizan a continuación:

El articulo 25 Constitucional considera a estas unidades como integrantes del sector social de la economía, pero esta sola mención no implica la facultad para legislar sobre ellos.

Por su parte el articulo 28 constitucional Párrafo $7 .^{\circ}$ otorga facultades para que sean los propios legisladores de los Estados quienes in-

${ }^{24} \mathrm{Cf}$. 
tervengan en materia de cooperativas, al efecto resulta interesante el comentario que realiza Alfonso Labriega pues sostiene que dicha intervención fue cuestionada en el debate del constituyente de 1917 por considerarla peligrosa solicitando se consignara en algún otro precepto como Facultad de Congreso de la Unión interpretándose que dicha intervención puede ser en materia administrativa o legislativa.

Producto de esta facultad legislativa por parte de los Estados fueron; la Ley de Sociedades Cooperativas Civiles para el Estado de Yucatán (C. F. R. Decreto No 533 de D. O. del Estado. de Guanajuato (26. IX. 1932) que como comenta dicho autor «Ninguna de las dos leyes se consideraron inconstitucionales».

Por su parte el articulo 73 Fracción X menciona:

El congreso tiene facultad:

X.- Para legislar en toda la republica sobre Hidrocarburos, minería, industria cinematográfica, comercio, juegos con apuestas y sorteos, intermediación y servicios financieros, energía eléctrica y nuclear y para expedir las leyes de trabajo reglamentarias del Art. 123.

Luego entonces, en base, a este artículo, al artículo 28 párrafo $7 .^{\circ}$ Constitucional y 124 Constitucional ¿podría decirse que existe concurrencia de facultades para legislar en materia de cooperativas?

El prestigiado investigador M. Salinas Puente sostiene que el único fundamento para legislar en esta materia sólo se encuentra en el artículo 73 fracción X Constitucional que faculta al congreso para legislar en materia de comercio y de esa facultad deriva la Ley General de Sociedades Cooperativas, pero cuyos artículos $1^{\circ}$ y 212 de la Ley de Sociedades Mercantiles erróneamente asimilan a las cooperativas como sociedades mercantiles esto es:

El Art. $1 .^{\circ}$ de dicha ley como hemos visto define a las cooperativas como mercantiles; y el artículo 212 expresa que estas unidades económicas se regirán por su legislación especial, en consecuencia como sostiene Salinas Puente: «de quitarse esas dos normas se quitaría la única base legal del cooperativismo».

La anterior declaración fue hecha ante las propuestas de reformas a la ley de cooperativas del 17 de abril del año 2000 las cuales fueron aprobadas por la LVII legislatura, pero nunca se discutieron en el Senado. Asimismo sostiene que dichas reformas eran inconstitucionales ya que en el caso de ser avaladas por el senado, dejarían sin fundamento legal al movimiento cooperativista. ${ }^{25}$

25 Periódico Excélsior. 1. e mayo de 2000, primera sección. 
En dichas propuestas se establece la derogación de la fracción VI del artículo $1 .^{\circ}$ y el artículo 212 de la ley de sociedades mercantiles, argumentándose que estas empresas pertenecen al sector social de la economía, disposición que es acorde con lo que establece el artículo 25 Constitucional.

Alfonso labriega citando a Rodríguez y Rodríguez, nos proporciona una explicación histórica del porqué las cooperativas son comprendidas en una legislación mercantil:

«No siendo calificada esta forma de organización mercantil, se escapaba a la Legislación Federal, en los términos del artículo 73 fracción $\mathrm{X}$ de la Constitución. Ello origina que los diversos Estados dictasen una legislación caótica sobre estas sociedades, que no podrían desarrollarse con tal diversidad legislativa. Por ese motivo y con el propósito de impulsar la difusión de las cooperativas al dictarse la ley de las sociedades mercantiles se incluyó con ellas a la cooperativa, como una forma mercantil más, a efecto de atraer su reglamentación a la competencia federal. ${ }^{26}$

Asimismo cita a Mantilla Molina mencionando que:

«Solo porque se trata de materia mercantil puede considerarse válida la Ley General de Sociedades Cooperativas que estableció el régimen de ellas para dar cumplimiento al mencionado artículo 212 de la Ley de Sociedades Mercantiles. De considerar civiles a las sociedades cooperativas habría que declarar inconstitucional la mencionada ley porque el legislador federal no es competente para dictar leyes en materia local, como lo es la materia civil». Y más adelante añade: "calificar a la cooperativa como mercantil ocasiona tener como supletoria a la legislación mercantil, particularmente a la Ley General de Sociedades Mercantiles en lo conducente y considerarla como comerciante». ${ }^{27}$

Por su parte la Suprema Corte de Justicia nada ha dicho al respecto, por lo tanto esta confusión en la ley ha traído como consecuencia la confusión en la naturaleza de las mismas empresas cooperativas en México.

Ya que las hace aparecer tanto sujetas al derecho privado como sujetas al derecho social, existiendo un abismo entre ambas, en virtud de que la clasificación tradicional del derecho se establece desde el punto

26 LABRIEGA, Pedro. ob.cit. p. 240.

27 Ídem. 
de vista dicotómico (derecho público y derecho privado) y el desarrollo social se concibe desde una apreciación tricotómica (derecho público, derecho privado y derecho social), definiendo al derecho social como: «una ordenación de la sociedad en función de una integración dinámica, teleológicamente dirigida a la obtención del mayor bienestar social de las personas y de los pueblos, mediante la justicia social». ${ }^{28}$

Por tanto resulta importante definir la naturaleza de estas organizaciones en la propia ley ya que no tendría caso hacer empresas sociales que funcionaran como empresas privadas.

- NÚMERO DE SOCIOS: Otro de los problemas existentes en las empresas cooperativas mexicanas que a nuestro juicio puede desvirtuar su naturaleza especial es el hecho de que la ley vigente redujo el Número de socios de diez a cinco, estableciendo que bastaba este número para constituir una sociedad cooperativa.

Ahora bien como hemos mencionado este problema repercute en el espíritu cooperativista de ayuda mutua que tenia como finalidad suplir la debilidad individual con el número de socios, además como puede observarse no ha sido nada favorable para el movimiento cooperativo, pues algunas personas han aprovechado esa ventaja para formar figuras asociativas, convirtiéndola en negocio de unos cuantos e incluso defraudando a sus propios socios en varias ocasiones sobre todo en las cooperativas de consumidores que se dedican a las actividades de ahorro y préstamo.

Lo mismo puede decirse de las cooperativas de productores quienes únicamente con cinco socios, se limitan a aportar el capital y los medios de producción, percibiendo los excedentes que genera la cooperativa, y para crecer simplemente se contrata a trabajadores.

Esta situación contradice unas de las finalidades del cooperativismo que es evitar en lo posible al trabajo personal subordinado pues conforme a los principios del cooperativismo una de las finalidades de este tipo de empresas es que los propios trabajadores sean los dueños de la misma y que los medios de producción sean propiedad social, ya que con ello se evita la subordinación y la distribución inequitativa. ${ }^{29}$

Por lo anterior resulta evidente a todas luces que la empresa cooperativa mexicana al igual que muchas empresas en el mundo esta sufriendo algunos cambios en sus valores fundamentales.

28 Díaz Lombardo, Francisco. El derecho social y la seguridad social integral. Serie Textos Universitarios. México Universidad Nacional Autónoma de México. 2. ${ }^{a}$ edición. 1978 p. 51.

${ }^{29}$ Véase iniciativa de reformas a la Ley General de Sociedades Cooperativas del año 2000. Comisión de Fomento Cooperativo VIX Legislatura Cámara de Diputados. 
- ACTUACIÓN ECONÓMICA: Otro aspecto importante que nos parece conveniente señalar es en el ámbito de la actuación económica de las sociedades cooperativas, toda vez que la ley actual y a diferencia de las anteriores leyes que han existido en lugar de declarar que las sociedades no sean lucrativas o especulativas, se estimó conveniente dejarse manejar sin limitar su participación de manera discriminatoria con respecto a otras figuras especialmente por lo que toca a sus oportunidades de acumulación y desarrollo. Asimismo se estimo conveniente que pueda participar en todos lo campos de la economía, que se desarrollan por completo, sin limitaciones en la totalidad del ciclo económico y con acceso al financiamiento con respaldo de fondos de garantía. ${ }^{30}$

Respecto a este punto simplemente se hace necesario acordar el peligro de renuncia a la igualdad de derechos y deberes de los titulares de las acciones, así como a la renuncia al sistema tradicional de excedentes en proporción a las operaciones realizadas por cada socio y a la renuncia al concepto tradicional del significado de propiedad cooperativa, la administración y la utilización de los servicios de la cooperativa, especialmente cuando se admitió a miembros que en la doctrina se les ha denominado "MINU» (miembros inversionistas no usuarios). ${ }^{31}$

En virtud de que esta situación podría traer consigo una evidente contradicción con los valores cooperativos de igualdad, equidad, solidaridad, esfuerzo propio, ayuda mutua, etc., ya que puede existir una desventaja en la distribución de los excedentes en proporción con las operaciones de los socios y las posibles ventajas del capital.

- FONDOS DE RESERVAS: En lo relativo a los fondos de Reservas, estamos de acuerdo en la propuesta que maneja la Comisión del Proyecto Cooperativo de Reformas 2000 respecto a los Fondos Sociales, toda vez que menciona que la ley actual dispone que estos fondos deben ser «discrecionales», aludiendo la mencionada comisión que no es conveniente esta situación, ya que es importante que toda persona moral tenga obligatoriamente fondos de esa naturaleza, pues el de reserva sirve como respaldo en caso de que la cooperativa sufra pérdidas y con el mismo pueda cumplir con las obligaciones contraídas. El de previsión social también resulta de gran trascendencia, pues es destinado a prestaciones de previsión social que son indispensables, fundamentalmente en una organización en que los socios aporten su trabajo físico, expuestos por lo tanto a sufrir riesgos de accidentes. Y por lo que toca al fondo de

30 Ídem. 
educación cooperativa es esencial a fin de que se pueda brindar a cada uno de los socios, la educación y capacitación para hacerlos partícipes activos en la propia empresa. ${ }^{32}$

Asimismo resulta necesario ante todo acentuar en la ley su naturaleza social, esto es; es necesario adicionar el artículo 2 de la ley vigente estableciendo que las organizaciones cooperativas son organizaciones sin fines de lucro aún cuando existan algunas semejanzas con la empresa privada.

Por otra parte es necesario recordar que la empresa cooperativa no percibe utilidades como las empresas privadas, mismas que son repartidas entre sus miembros en razón a los aportes al capital o se destinan a la capitalización de la empresa, sino que en las empresas cooperativas, los excedentes que se obtienen no se distribuyen en relación, a los aportes de los asociados, sino que son destinados a incrementar las reservas legales, a formar fondos de beneficio social, de educación o asignando a los miembros beneficios cooperativos en proporción: en las cooperativas de consumidores al uso que los asociados hayan hecho de los servicios de la entidad, que significa una devolución de parte de lo pagado al hacer las adquisiciones y en el caso de las cooperativas de productores es una adición o complemento a lo inicialmente percibido por su trabajo.

Como se observa el concepto de excedentes cooperativo difiere grandemente de la idea de utilidad de la empresa capitalista, pudiendo tener la posibilidad de que el excedente pueda ser repartido entre sus miembros o bien cubrir finalidades de tipo social o cultural.

Por lo anterior es necesario evitar en lo posible en la ley General de Sociedades Cooperativas que:

- Se requieran sumas adicionales a los nuevos miembros de acuerdo con las reservas cooperativas de los últimos años.

- Que se reconozca prioridad alguna a los inversores (sean o no sean miembros de la empresa) sobre todo en los casos de disolución y liquidación de la empresa cooperativa ó por sobre los derechos de los socios usuarios de los servicios de la cooperativa.

- Que se destine el saldo de las operaciones de revalúo del capital de las cooperativas tanto a reservas de la entidad, como a la capitalización de sus miembros, ya que con ello se resaltarían los intereses económicos y financieros de las personas involucradas en las cooperativas y se minimizaran los caracteres sociales y solidarios de la misma.

32 Artículos 16 y 55 de la Ley General de Sociedades Cooperativas. 
Lo que significa en conclusión: que no se deben destacar los intereses pecuniarios individuales por sobre los intereses comunes, ni se debe priorizar los derechos a los inversores «no usuarios» ya que a ellos dolo puede interesarles el resultado financiero de sus operaciones, violándose con ello los principios de igualdad, equidad y solidaridad.

- PERSONAS EXTRAÑAS: Otro punto importante que merece la pena resaltar es lo relativo a la participación de personas o actividades tradicionalmente extrañas.

Pues bien, como quedo asentado anteriormente se ha visto que conforme a la tradición cooperativa y conforme a la práctica legal, los propios socios cooperativistas eran los encargados de la administración de la empresa, frente a ellos se observa en nuestra actual legislación que personas extrañas pueden participar en la organización o en el funcionamiento interno de las mismas dentro del consejo de administración. Ocasionalmente con ello graves problemas (artículos 45 y 46 de la Ley general de Sociedades Cooperativas).

Lo anterior lo podemos observar con los problemas que se han suscitado en los últimos años en la cooperativa denominada «periódico Excelsior» en el que según se afirma se cometieron diversos desfalcos y abusos por parte de su administrador único, contratándose créditos en exceso, celebrando contratos leoninos que desangraron y comprometieron el patrimonio de la cooperativa, para posteriormente ofrecerla en venta como si fuera de su propiedad.

Como puede observarse no puede prohijarse en la administración de las cooperativas a personas tradicionalmente extrañas, con el argumento de su capacitación administrativa, por lo que se sugiere procurar la búsqueda de solución a esos problemas que afectan los rasgos fundamentales que caracterizan su funcionamiento como actividades cooperativas.

- COMPLEJIDAD DE NORMAS: La creciente diversidad y complicación de normas aplicables es otro de los problemas a que se enfrenta actualmente la empresa cooperativa en México pues como ya se ha dicho no puede perderse de vista el origen que tuvieron las empresas cooperativas, que se extendieron por todo el mundo como instrumentos de servicio a los amplios sectores de la población, que vieron en ellas instrumentos útiles que les permitieron satisfacer adecuadamente sus necesidades y dar solución a sus problemas socioeconómicos y en general elevar el índice de vida.

Por ello es tan importante que sean los propios cooperativistas quienes manejen la organización de sus entidades, siendo indiscutible que 
las normas sean claras, precisas y al alcance de todos, para que los socios participen activamente en su funcionamiento, asimismo es importante la educación cooperativa para el manejo, control e información acerca de su empresa.

Diversas son las disposiciones que a nuestro juicio merecen modificarse en nuestra Ley General de Sociedades Cooperativas, pues al parecer prescinden de esa simplicidad y claridad para poder aplicar fácilmente las normas.

Esa complejidad en nuestra ley vigente contradice sin duda el carácter popular y democrático que las entidades cooperativas deben tener, lo cual puede acarrear dudas y discrepancias como se ha venido observado en el presente análisis.

- EDUCACIÓN COOPERATIVA: La amenaza de la desnaturalización de las empresas cooperativas en parte de debe a la ignorancia y falta de educación sobre las mismas, pues consideramos que la educación cooperativa que actualmente se imparte en nuestro país ha sido escasa.

Consideramos asimismo que debe ser un requisito indispensable el formar a la niñez y juventud en la ayuda mutua, en la colaboración recíproca, en la transformación de la actual economía de mercado en una economía de servicios de motivar la superación del individuo para ello se requiere que las empresas cooperativas destinen parte de sus utilidades a la enseñanza cooperativa.

La orientación de la persona debe ser considerada desde una perspectiva interna y la empresa cooperativa cumple con esa condición en donde prima el factor humano sobre el factor capital, bajo un claro esquema de valores y principios que definen al cooperativismo y orientan el comportamiento de las cooperativas a título individual y colectivo. Siendo evidente que esos valores y principios conforman una cultura y una determinada manera de pensar y hacer.

La identidad cooperativa como se ha visto a o largo del trabajo sintoniza con valores arraigados a la sociedad actual como la: Democracia, la igualdad, la seguridad, la solidaridad, etc. Lo cual resulta sumamente importante en la medida que una empresa no le sea ajena a la sociedad, de ahí que las empresas cooperativas sepan agregar a los bienes y servicios los valores que requiere la sociedad actual.

Este es el aspecto más crítico del desarrollo del cooperativismo Mexicano pues desde hace varios años existían instituciones especiales especializadas en la investigación y educación cooperativa, que hoy ya no existen. En algunas instituciones sin embargo se imparten una serie de cursos, pláticas y seminarios en diferentes instituciones y a juicio de va- 
rias organizaciones es imposible ofrecer cursos superiores por falta de personal docente calificado.

De hecho la única universidad en nuestro país que contempla la enseñanza cooperativa es la Universidad Autónoma de Querétaro que desde hace varios años (40 años), bajo el nombre de: Técnico en Cooperativas, y actualmente (2009) eleva dicha enseñanza a carrera universitaria bajo el nombre de: Gestor de Empresas Sociales.

- LIDERAZGO: Otra situación importante que fortalece la naturaleza de la empresa cooperativa es la figura del liderazgo.

En efecto se debe cultivar el liderazgo que es otra de las situaciones que hace falta fortalecer en nuestras empresas cooperativas Mexicanas, más no el líder tradicional del que se espera que cargue sobre sus hombros todo el peso de la empresa, sino el que es capaz de crear el ambiente propicio para que cada integrante de la organización soporte la carga que lo corresponde.

El cooperativismo por la condición democrática de sus dirigentes esta en la mejor condición de asumir este papel de liderazgo, observándose sin embargo en nuestro país que aún adolecemos de diversos problemas, ya que no contamos con un perfil de líder, existiendo si acaso un conjunto de estereotipos que en muchas ocasiones no responde a las necesidades de la región.

Asimismo se carece de una cultura de rendición de cuentas y transparencia que incluya a sus dirigentes.

Por todo ello puede decirse que existe la necesidad para nuestras empresas cooperativas de crear perfiles de liderazgo, que puedan marcar hacia el futuro decisiones estratégicas lo cual resulta vital hoy en día. Los procesos de visión y misión de las cooperativas es algo que debe ser asumido fundamentalmente por sus dirigentes como puede ser: la formación de capital, los marcos legales, la integración, etc.

Consideramos que la formación de líderes debe asumir un rol no solamente motivador, sino que deberá permitir señalar cuales son los caminos más adecuados para las empresas cooperativas.

Las decisiones estratégicas impulsadas por sus líderes deberán estar enmarcadas en procesos conjuntos de todo el movimiento cooperativo, lo cual implica una red de los líderes bien organizados y coordinados con objetivos comunes bien identificados.

- LEY DE AHORRO Y CRÉDITO POPULAR: La aprobación por parte de la Cámara de Diputados (26 de octubre de 2001) respecto de la «Ley de Ahorro y Crédito Popular» a nuestro juicio es un intento de desnaturalizar tanto a la empresa cooperativa como al movimiento 
cooperativo dado el desconocimiento de carácter social de las mismas a quienes se les pretendió dar un trato idéntico al otorgado a cualquier institución privada.

El diputado perredista Manuel Duarte comento al aprobarse ese dictamen: "Si la intención es desaparecer a estas empresas cooperativas al ponerlas a competir en el mercado abierto con las sociedades anónimas que los promotores de la ley lo digan abiertamente». ${ }^{33}$ Opinión que hacemos nuestra.

Por otra parte era necesaria la creación de esta ley ya que con la crisis financiera, iniciada en finales de 1994 se había dirigido el financiamiento hacia el sector privado de la economía con más de un $80 \%$, lo que orilló a muchas empresas a acudir a intermediarios no bancarios para satisfacer sus requerimientos, sin embargo como se ha dicho ello no significaba que debiera darse a esta empresa un trato igual al de cualquier institución privada ya que esto representa un total desconocimiento del carácter social que estas empresas deben tener. Dicha ley no debe constituir una amenaza para el sistema cooperativo nacional.

En la elaboración del dictamen se reformaron y drogaron algunas disposiciones de la ley General de Organizaciones y actividades auxiliares de crédito y de la misma ley general de Sociedades Cooperativas, pues con ello se trató de subsanar una ausencia legal.

- AGRUPACIÓN ENTRE COOPERATIVAS: Un último análisis que nos parece pertinente realizar es el relativo a las agrupaciones de las empresas cooperativas, en efecto, el texto actual del artículo 74 de la ley General de Sociedades cooperativas resulta confusa y con efectos desintegradores ya que al mencionar que: "Las sociedades cooperativas se podrán agrupar libremente en federaciones, uniones o en cualquier otra figura asociativa con reconocimiento legal», ha provocado un gran desorden, puesto que a raíz de la desaparición de la vigencia del Estado, los mecanismos de integración nacional se debilitaron propiciando que con tres cooperativas de diferentes ramas de actividad se forme una unión, y con diez de ellas una confederación Nacional, resulta que con 30 sociedades cooperativas se forma una confederación, esto da como resultado un gran número de organizaciones sin la fuerza necesaria ni la representación ${ }^{34}$ como puede observarse esta situación obliga a que se replante nuevamente el texto de la mencio-

\footnotetext{
33 Periódico Excelsior 24 de abril 2001. Sección primera

34 Texto tomado de la Asamblea celebrada durante el Primer Congreso Nacional Cooperativista. Junio 2001. en la Ciudad de México DF.
} 
nada ley a efecto de estar acorde con la realidad y con los tiempos que estamos viviendo.

De hecho, podrían citarse una gran multitud de problemas por lo que actualmente atraviesa la empresa cooperativa, siendo los aquí vertidos los más representativos ya que como hemos mencionado son los que tienden a desvirtuar los valores y principios que distinguen a estas empresas de las demás, en consecuencia no nos resta sino hacer nuestra la opinión que emite la Comisión de Fomento Cooperativo para las reformas del 2000 que menciona:

«Históricamente el movimiento cooperativo mexicano ha formado parte del movimiento cooperativo internacional, reconociendo en la Alianza Cooperativa Internacional, (A.C.I) un interlocutor y el órgano de discusión y formulación de la doctrina cooperativa, la última revisión de los principios universales del cooperativismo que rigen el funcionamiento de toda sociedad cooperativa en cualquier parte del mundo fue hecha en el congreso de dicho órgano interlocutor, celebrado en el mes de septiembre de 1995 en Manchester Inglaterra». ${ }^{35}$

En el citado congreso además de la reformulación de los principios universales del cooperativismo, la Alianza Cooperativa Internacional emitió por primera vez en la historia una definición del concepto de cooperativa y señalo el conjunto de valores éticos que definen denominada entidad cooperativa.

Como se observa la Ley General de Sociedades cooperativistas vigente (1994) no obstante que tuvo el mérito de haber actualizado su contenido no pudo haber tomado en cuanta la última versión de la Alianza Cooperativa Internacional en la que quedaron plasmados los principios universales del cooperativismo emitido en 1995.

En base, a esta declaración ( $\mathrm{ACl}$ ) y ante los problemas anteriormente planteados se propone:

\section{c) Propuestas}

- Respecto al primer punto se establece la necesidad de definir la naturaleza jurídica de la sociedad cooperativa, dado que actualmente no se encuentra claramente definida como hemos visto, en virtud de que por una parte la Ley de Sociedades Mercanti-

35 Propuesta de reformas a la Ley General de Sociedades Cooperativas, año 2000 Comisión de Fomento Cooperativo VIX legislatura Cámara de Diputados. 
les en su artículo $1 .^{\circ}$ la reconoce como sociedad mercantil, y por otra el artículo 25 de nuestra Constitución Política la considera como parte integral del sector social de la economía, en consecuencia se propone reformar la constitución, en la inteligencia de conceder al Congreso de la Unión la facultad «expresa « para legislar en relación, a las sociedades cooperativas adicionando la fracción $X$ del artículo 73 Constitucional, ya que solo de esta manera se podría contar con una ley especial para este tipo de entidades.

- En el punto relativo a la reducción del número de miembros que en la ley vigente es de 5 miembros, se propone la modificación del artículo 11 de la ley en comento, pues tomando en cuenta que este tipo de organizaciones se propone suplir la debilidad individual mediante la fuerza del número es a través de la unión como compensa su debilidad individual, en consecuencia se propone aumentar a 10 personas como mínimo para la constitución de la sociedad, toda vez que de esta manera se podrán rescatar sus valores fundamentales que distinguen a estas empresas, y respecto a las cooperativas de consumo dedicadas a la actividad de ahorro y préstamo, se propone que se integren con el número de 200 socios como mínimo dada la finalidad de éste tipo de organizaciones ya que a medida que este numero sea mayor, podrá cumplir mejor sus objetivos como es captar el ahorro de sus miembros y colocarlo entre ellos mismos.

- Así mismo se propone que la Ley de Ahorro y Crédito popular, no se esquematicen dentro de la corriente financiera en forma general sino que tome en cuenta la naturaleza jurídica de la Sociedad Cooperativa de Ahorro y Préstamo y su función dentro de la sociedad, puesto que la ley actual les ha dado un trato igual al de cualquier institución privada, poniéndolas a competir en el mercado abierto con las sociedades anónimas, desconociendo con ello su naturaleza especial y dada la actividad que realizan, por lo tanto debería agregarse un párrafo en el que se establezca que las cooperativas de esta naturaleza se regirán por su propia ley( Ley General de Sociedades Cooperativas), dado que actualmente se encuentran reguladas en forma especial y supletoria por las disposiciones de la legislación mercantil y bancaria, que nada tiene que ver con el espíritu asociativo y solidario, todo ello con la finalidad de fortalecer la confianza y la credibilidad de las actividades financieras en estas empresas.

- En lo relativo a la formación de capital de estas entidades, no debe perderse de vista todos y cada uno de los esfuerzos que 
se han hecho por parte del movimiento cooperativo, tanto en las cooperativas de ahorro como en las cooperativas en general, ya que requieren de capital pero sin que pierdan el marco legal de su identidad cooperativa, pues la capacidad de formación de capital es estas entidades a diferencia de las demás, repercute directamente en la posibilidad de: capacitación, formación, asistencia técnica, etc. Por tanto deben promoverse eventos y acciones tendientes de reflexión, a fin de que las cooperativas encuentren los mecanismos adecuados de formación de capital que se adapten a su propia identidad.

- Se propone adicionar el artículo 2 de la ley en comento estableciendo que las cooperativas son: "organizaciones sin fines de lucro», pues como se ha mencionado la ley de 1994 no define correctamente la naturaleza de la sociedad cooperativa que para ser fiel a los principios del derecho cooperativo no deben percibirse utilidades sino que se deben formar fondos de beneficio social, de educación etc. asi como asignar a los miembros los beneficios económicos en proporción al uso ( en las cooperativas de consumidores) que los asociados hubieren hecho de los servicios de la entidad y en el caso de las cooperativas de productores es una adición o complemento a lo recibido inicialmente por su trabajo, de donde el excedente cooperativo no es igual a la idea de utilidad ó lucro

- En lo relativo a los fondos sociales como son de reserva y de previsión social artículo 53 de la ley vigente, se propone modificar su «discrecionalidad» ya que se considera importante que las cooperativas tengan obligadamente fondos de esa naturaleza por ser fundamentales e indispensables para que la propia organización pueda contar con recursos necesarios a fin de solventar sus obligaciones.

- Se propone modificar el artículo 41 y 42 a efecto de que los miembros del Consejo de Administración puedan ser reelectos cuando las dos terceras partes de los socios que asistan a las asambleas lo aprueben, dado que en las cooperativas que se integran con muchos socios, especialmente las de ahorro y préstamo resulta difícil reunir al total de los miembros. Asimismo se propone que los miembros del Consejo de Administración sólo sean reelectos una vez y que al concluir su gestión no ocupen cargo alguno en el Consejo de Vigilancia ni de Gerentes en el periodo inmediato posterior, salvo en aquellas empresas cooperativas integradas por lo menos de 20 socios, impidiendo con ello que las empresas se encuentren indefinidamente al frente 
de las cooperativas y evitando que los miembros de dichos órganos de representación se mantengan siempre al frente de la organización, así mismo se propone buscar los medios adecuados para que sean los propios cooperativistas quienes tengan dichas funciones, manteniendo actualizados a todos los miembros de la empresa sobre las experiencias de su legislación y sobre los esfuerzos que se realicen para su mejoramiento.

- Se propone que nuestra legislación cooperativa retome con toda formalidad el tema de la educación cooperativa (artículos 59 y 90) ya que esta es esencial a todos los niveles, y es de suma importancia que el movimiento cooperativo invierta en la promoción de la imagen de la cooperativa y que explique al mundo que la diferencia se basa en sus valores y principios fundamentales.

- Se propone así mismo que la legislación cooperativa sea más clara para el efecto de que este al alcance de todos los miembros de la empresa ya que de esa manera podrán participar directamente en todas y cada una de sus actividades desde el aspecto técnico, hasta el manejo administrativo de la organización, pues esa complejidad de que adolece actualmente en la estructura de sus normas contradice sin duda el carácter popular y democrático que las entidades cooperativas deben tener. En el título III de la ley se proponen cambios a los organismos de integración de las sociedades cooperativas, con la finalidad de hacer mas puntuales y explícitos los requisitos y procedimientos para su formación, pues actualmente existen algunas confusiones al respecto, esto es que la ley actual menciona que es factible para estos organismos integrarse en organismos de $2 .^{\circ}$ Grado, lo cual atenta contra el principio del cooperativismo relativo a la «cooperación entre cooperativas», puesto que el cooperativismo es un sistema universal cuyo fin es crecer y coadyuvar al desarrollo de las naciones, en consecuencia se propone que la integración de la sociedad cooperativa sea obligatoria y aclarar la manera como se integran las uniones, las federaciones y las confederaciones a efecto de clarificar la ley y hacerla mas explícita y al alcance los miembros de la cooperativa.

- Se propone definir en la ley, los mecanismos que procuren la formación de nuevas personas líderes, así como la creación de mecanismos que procuren por un lado el buen desempeño del líder y por otro su rendición de cuentas. Para ello es necesario proponer redes orientadas a la capacitación, de autodesarrollo e intercambio de experiencias sobre el liderazgo, fortaleciendo la capacidad y la calidad de las propias cooperativas. 
- Se propone desaparecer la figura de las uniones,(articulo 74) así como que: las sociedades cooperativas se agrupen en federaciones estatales, y a su vez estas en confederaciones Nacionales por rama de actividad económica. pues debemos reconocer que en el entorno actual las empresas cooperativas son cada vez más víctimas de los ataques del sector privado debido sobre todo a la falta de su conocimiento y de sus fines, por lo que para invertir esta tendencia es necesario que las cooperativas a nivel regional y nacional respeten el principio de cooperación entre cooperativas formando sus propias alianzas, para garantizar que también ellas y no sólo el sector privado puedan beneficiarse con algunas de las oportunidades que brinda la globalización ya que con ello no solo se favorece a sus miembros sino que a la postre beneficiará también a la comunidad en la que operan, pero sin perder jamás su naturaleza específica y sus principios fundamentales sobre los que se encuentran sustentadas.

\section{Bibliografía}

GonzÁlez Díaz Lombardo, Francisco. El Derecho Social y la Seguridad Social Integral. Serie Textos Universitarios. Editorial UNAM. México. 1978.

Hinostroza Fernández, Luís. Movimiento Cooperativo Internacional. Cooperativismo y sector social en México. Universidad Autónoma Metropolitana. Méx. 1989.

Kaplan De Drimer, Alicia. Mutaciones estructurales en las cooperativas. Ministerio de Trabajo y Asuntos Sociales y Dirección General de Fomento a la Economía Social. Editorial. CIRIEC. España 1997.

Labriega Villanueva, Pedro A. La Reforma de Legislación Mercantil (Recopilación). Editorial. Porrúa S.A. Méx. 1985.

Revista Mexicana del Trabajo. Datos históricos sobre el cooperativismo en México. Quinta época. Tomo IX Méx. DF. 1972.

Revista de Comercio Exterior. Evaluación del cooperativismo Mexicano. Volumen No. 36 N. 9 Méx. DF. 1986.

Revista UNIRCOOP Américas. Volumen 1 numero 2. noviembre de 2003. Universidad de Sherbrooke.

RUIZ DE CHÁvez, Mario. Apuntes inéditos tomados de la cátedra: Cooperativismo en México. Universidad Nacional Autónoma de México .1999.

Serie Conciencia Cooperativa. Fuente: Elementos del cooperativismo. Instituto Mexicano de Estudios Cooperativos A.C. Méx. spge 1982.

Exposición de motivos de la Ley General de Sociedades Cooperativas de 1927. Exposición de motivos de la Ley General de Sociedades Cooperativas de 1933. Exposición demotivos de la Ley General de Sociedades Cooperativas de 1938. Exposición de motivos de la Ley General de Sociedades Cooperativas de 1994. 
Iniciativa de Reformas a la Ley General de sociedades Cooperativas. (2000) Comisión de Fomento Cooperativo de la VIX Legislatura. H. Cámara de Diputados del Congreso de la Unión.

Constitución Política de los Estados Unidos Mexicanos. Edit. Porrúa. Méx. 2000.

Ley General de Sociedades Cooperativas del año 1927.

Ley General de Sociedades Cooperativas del año 1933.

Ley General de Sociedades Cooperativas del año 1938.

Ley General de Sociedades Cooperativas del año 1994.

Código Civil para el Distrito Federal. Ediciones Delmar S.A. de C.V. México.

Código de Comercio. Leyes Complementarias. Colección Porrúa. 56ava Edición.

Ley Federal del Trabajo. Edit. Porrúa. 1992.

Ley del Seguro Social. Ediciones Fiscales ISEF. S.A. Méx. 1996.

http//www.cudecoop.org.uy/revista/revistas/0796.html

http//www.alianzaaci.or/planes/plan.estratégico.html

http//www.copo.org/ica/es/esprinciples.html

http//www.alianza.aci.or.cr/marcosleg/dante.cracogna.html

http//www.copo.org/ica/es/intros.html 